\title{
Plasma Spray-PVD: A New Thermal Spray Process to Deposit Out of the Vapor Phase
}

\author{
Konstantin von Niessen and Malko Gindrat
}

(Submitted December 13, 2010; in revised form March 23, 2011)

\begin{abstract}
Plasma spray-physical vapor deposition (PS-PVD) is a low pressure plasma spray technology recently developed by Sulzer Metco AG (Switzerland). Even though it is a thermal spray process, it can deposit coatings out of the vapor phase. The basis of PS-PVD is the low pressure plasma spraying (LPPS) technology that has been well established in industry for several years. In comparison to conventional vacuum plasma spraying (VPS) or low pressure plasma spraying (LPPS), the new proposed process uses a high energy plasma gun operated at a reduced work pressure of $0.1 \mathrm{kPa}(1 \mathrm{mbar})$. Owing to the high energy plasma and further reduced work pressure, PS-PVD is able to deposit a coating not only by melting the feed stock material which builds up a layer from liquid splats but also by vaporizing the injected material. Therefore, the PS-PVD process fills the gap between the conventional physical vapor deposition (PVD) technologies and standard thermal spray processes. The possibility to vaporize feedstock material and to produce layers out of the vapor phase results in new and unique coating microstructures. The properties of such coatings are superior to those of thermal spray and electron beam-physical vapor deposition (EB-PVD) coatings. In contrast to EB-PVD, PS-PVD incorporates the vaporized coating material into a supersonic plasma plume. Owing to the forced gas stream of the plasma jet, complex shaped parts such as multi-airfoil turbine vanes can be coated with columnar thermal barrier coatings using PS-PVD. Even shadowed areas and areas which are not in the line of sight of the coating source can be coated homogeneously. This article reports on the progress made by Sulzer Metco in developing a thermal spray process to produce coatings out of the vapor phase. Columnar thermal barrier coatings made of Yttria-stabilized Zircona (YSZ) are optimized to serve in a turbine engine. This process includes not only preferable coating properties such as strain tolerance and erosion resistance but also the simultaneous coverage of multiple air foils.
\end{abstract}

Keywords ceramic oxide layers, coatings for gas turbine components, low pressure plasma spray

\section{Introduction}

A common feature of the thermal spray processes is that the coating build-up is performed by a spray of molten or semi-molten coating material. Conventional vacuum plasma spray processes usually operate at pressures above $3 \mathrm{kPa}$ (30 mbar) (Ref 1). In contrast to thermal spray technology, the working pressure of physical vapor deposition (PVD) processes is much lower and can vary from $5 \mathrm{~Pa}\left(5 \times 10^{-2}\right.$ mbar $)$ to $0.1 \mathrm{~Pa}(1 \times$ $10^{-3}$ mbar), and sometimes even lower (Ref 2-4). With PVD, the coating material condenses directly on the substrate out of a vapor cloud. This enables us to produce coatings with characteristics which are not yet achievable with any of the existing thermal spray processes. PVD coatings are very homogeneous, thin, dense, hard, gas tight, and have specially designed microstructures. For

Konstantin von Niessen and Malko Gindrat, Sulzer Metco AG, Rigackerstr. 16, CH-5610 Wohlen, Switzerland. Contact e-mail: konstantin.vonniessen@sulzer.com. instance, the columnar microstructure of yttria-stabilized zirconia (YSZ) deposits obtained using electron beamphysical vapor deposition (EB-PVD) is especially suitable for highly strain-tolerant thermal barrier coatings (TBCs). The drawbacks of conventional PVD processes are the high investment costs and the low deposition rates. For this reason, this technology is mainly used for mass production thin film applications or production of thick TBC coatings on top of valuable components such as turbine vanes for aircraft engines. However, one limitation of conventional PVD is that it is a line-of-sight process. Only surfaces which are in direct line-of-sight to the coating source can be coated. Therefore, components with complex geometries and shadowed areas are very difficult to coat homogeneously.

The challenge taken by Sulzer Metco in this domain is to combine the advantages of thermal spraying, namely, the high coating quality, high deposition rates, and low investment costs with the possibility to produce coatings out of the vapor phase using plasma spray technology. This would afford a main advantage in the coating performance and would expand the field of application of thermal spray by opening up a whole new market and future growth perspective. From this point of view, Sulzer Metco has been successful in modifying a standard low pressure plasma spray (LPPS) process into a vaporcapable deposition process which is called plasma sprayphysical vapor deposition (PS-PVD). Unlike other PVD 
technologies, this process has the ability to coat areas which do not fall within the line-of-sight of the coating source. This allows the complete coverage of parts having complex geometries and shadowed areas, such as multiple turbine air foils or double vanes.

\section{PS PVD Technology}

The PS-PVD process is based on the ChamPro ${ }^{\mathrm{TM}}$ technology of Sulzer Metco which comprises all those thermal spray processes performing under a defined and controlled atmosphere, such as LPPS, VPS, and LVPS (Ref 1). These processes operate under reduced pressure conditions, typically in an argon gas atmosphere. The common working pressure of vacuum thermal spray processes range between 3 and $20 \mathrm{kPa}$ (30 and $200 \mathrm{mbar}$ ), which allows for the deposition of coatings having a typical thickness range between 20 and $2 \mathrm{~mm}$. This technology is widely adapted in the aero industry to deposit high-temperature oxidation-resistant layers and bond coats. The reduced pressure compared to atmospheric conditions enlarges the plasma plume from 50 to $500 \mathrm{~mm}$ in length and from 10 to $40 \mathrm{~mm}$ in diameter. A larger plume results in a bigger spray spot. Therefore, particle velocities and temperatures are more homogenously distributed over the cross section of the plume (Ref 5). This allows for production of coatings with a homogenous coating thickness distribution even on parts with complex geometries, in particular, turbine components.

\subsection{PS-PVD System Equipment}

The PS-PVD process operates at lower pressures down to $0.05-0.2 \mathrm{kPa}(0.5-2 \mathrm{mbar})$. Under these conditions, the properties of the plasma jet change substantially (Ref 6).

The plasma plume expands to more than $2 \mathrm{~m}$ long and $200-400 \mathrm{~mm}$ in diameter (Ref 7, 8). Figure 1 shows the effect of the pressure on the plasma length for air plasma spray (APS), VPS/LPPS and PS-PVD.

A modified single cathode vacuum plasma gun, the Sulzer Metco O3CP gun, allows for a high total gas flow of up to 200 SLPM and high power levels up to $180 \mathrm{~kW}$ (3000 A). The gun can be run with either a two- or fourfold internal powder injection. Pre-heating and cleaning of the substrate can be performed by the plasma itself or by means of an integrated transferred arc processing to optimize the coating adhesion.

The PS-PVD working pressure of $0.1 \mathrm{kPa}$ is still much higher than the one used in conventional PVD processes. Nevertheless, the combination of a high-energy plasma gun and a low-pressure environment enables achieving a predefined evaporation of the injected powder material. This allows for a controlled deposition to be produced out of the vapor phase. In EB-PVD, the transport of the vaporized coating material toward the substrate is carried out via a diffusion process with a limited throughput, thus producing coatings at low growth rates. In contrast with the PS-PVD process, the vaporized coating material is transported in a hot and supersonic gas stream
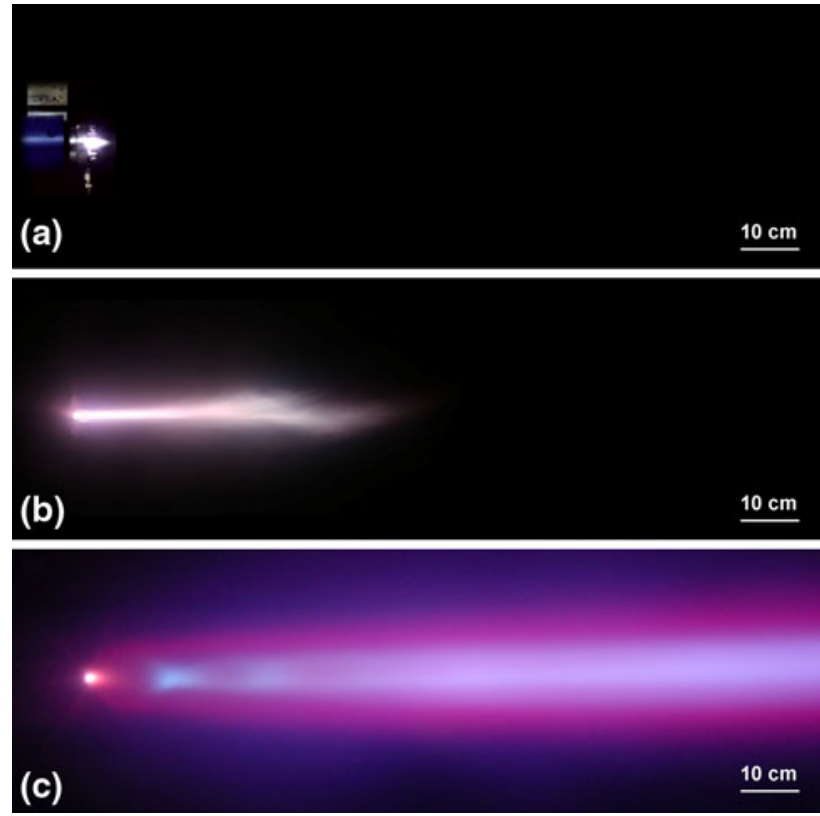

Fig. 1 Images of the plasma jets expanding at different pressures (a) $95 \mathrm{kPa}$ (950 mbar/APS), (b) $5 \mathrm{kPa}$ (50 mbar/VPS/ LPPS), and (c) $0.1 \mathrm{kPa}(1 \mathrm{mbar} / \mathrm{PS}-\mathrm{PVD})$

(2000-4000 $\mathrm{m} / \mathrm{s}$, and to $6000-10000 \mathrm{~K}$ in the plasma core) that expands in a $0.1 \mathrm{kPa}(1 \mathrm{mbar})$ atmosphere, leading to high growth rates and the ability to coat undercuts and areas which are not in the line-of-sight.

\subsection{Process Conditions and Characterization}

In order to monitor and characterize the evaporation and deposition process, several diagnostics are installed on the PS-PVD system. Standard diagnostic tools, such as the DPV-2000 or Acuraspray (Tecnar Automation Ltd., Canada), are usually employed to detect and measure the particles velocity and temperature in-flight when they are in the molten state inside the plasma jet. Since evaporated particles cannot be detected by these conventional techniques, optical emission spectroscopy (OES) can be employed to characterize and quantify the emission of the evaporated particles inside the plasma jet.

An infrared camera [Pyroview 380G] (DIAS Infrared Systems, Dresden, Germany), an infrared pyrometer [IGA 5] (Impac, Frankfurt, Germany), and thermocouples [Type K and N] (Thermocoax, Flers Cedex, France) are employed to measure and control the substrate temperature during the coating process. In addition, a fast CCD Camera [Pixelfly] (PCO, Kelheim, Germany) with a telezoom lens is employed to monitor the injection of the powder at the nozzle exit and also to analyze the stream of the supersonic plasma jet around the coated substrate during the coating process. Experimental investigations of the plasma jet in addition to the study of spray particle properties have demonstrated the special characteristics of this process, which are described in detail elsewhere (Ref 9-11). 


\section{Coating Development}

One of the main focuses of the coating development using PS-PVD is to produce a high-temperature-resistant TBC similar to EB-PVD coatings for turbine applications. The main aim is to deposit a coating having a columnar microstructure capable of achieving high strain tolerance, sufficient erosion resistance, and a low thermal conductivity. All developed coatings have been benchmarked with respect to other existing coating solutions for of turbine parts.

\subsection{TBC with Columnar Microstructure}

To ensure the evaporation of the coating material, a fine grain-sized powder feedstock $(<25 \mu \mathrm{m})$ is utilized. An 8 wt. \% YSZ powder Metco 6700 has been developed specifically for this purpose. To ensure the penetration of the powder deep into the plasma core, it is injected inside the plasma gun. With this particular powder and new PS-PVD technology, we can produce EB-PVD-like coatings in terms of having a columnar microstructure. Various types of microstructures can be produced by changing the process conditions. Figure 2 shows two coatings made with different spray parameters. The type of layer structure can be controlled by the spray parameters, turning it from a splat-type layer (see Fig. 2a) to a porous coating type, and finally to a columnar structure. The condition used for obtaining the columnar structure

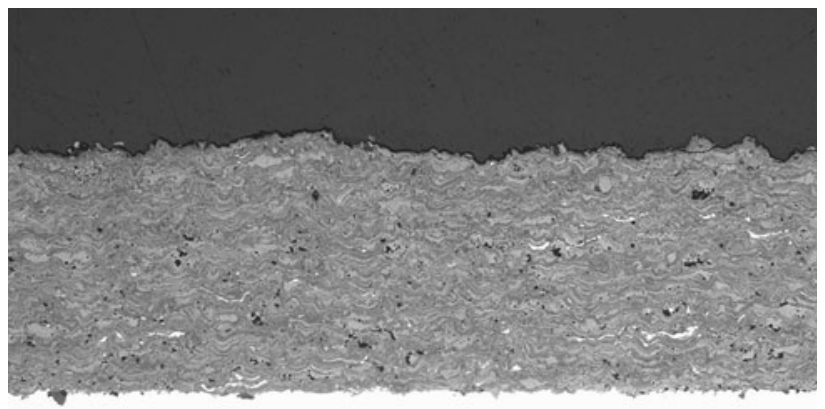

(a)

\section{$200 \mu \mathrm{m}$}

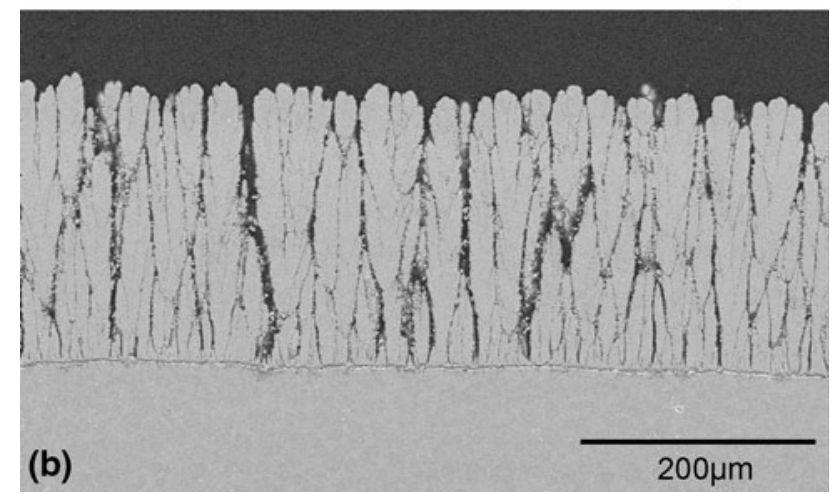

Fig. 2 TBC coating of 7YSZ using different PS-PVD plasma parameters showing (a) splat-like structure, and (b) columnar structure as shown in Fig. 2(b) is achieved by combining a low powder feed rate, a specific mixture of argon, and secondary plasma gases and by having a large spray distance.

Optical emission spectroscopy (OES) was employed to verify if specific plasma parameters have a measurable influence on the injected material inside the plasma jet. Figure 3(a) shows the spectrum of the plasma jet with injected YSZ powder using plasma parameters designed to produce splat-like coatings. The intensity of the spectral lines coming from the YSZ species is low, which shows that only a minor amount of the coating material is evaporated. In Fig. 3(b), the spectrum presents an increased overall intensity of the spectral YSZ lines which cover the full-wavelength bandwidth of the spectrometer $(350-900 \mathrm{~nm})$. The spectral lines correspond to the different species contained within the YSZ, namely, zirconium and yttrium. Here, the injected material could be vaporized which allows the growth of columnar-structured coatings.

Typical substrate temperatures during the spray process can vary between 900 and $1100{ }^{\circ} \mathrm{C}$ depending on the spray conditions and the substrate material. In general, a
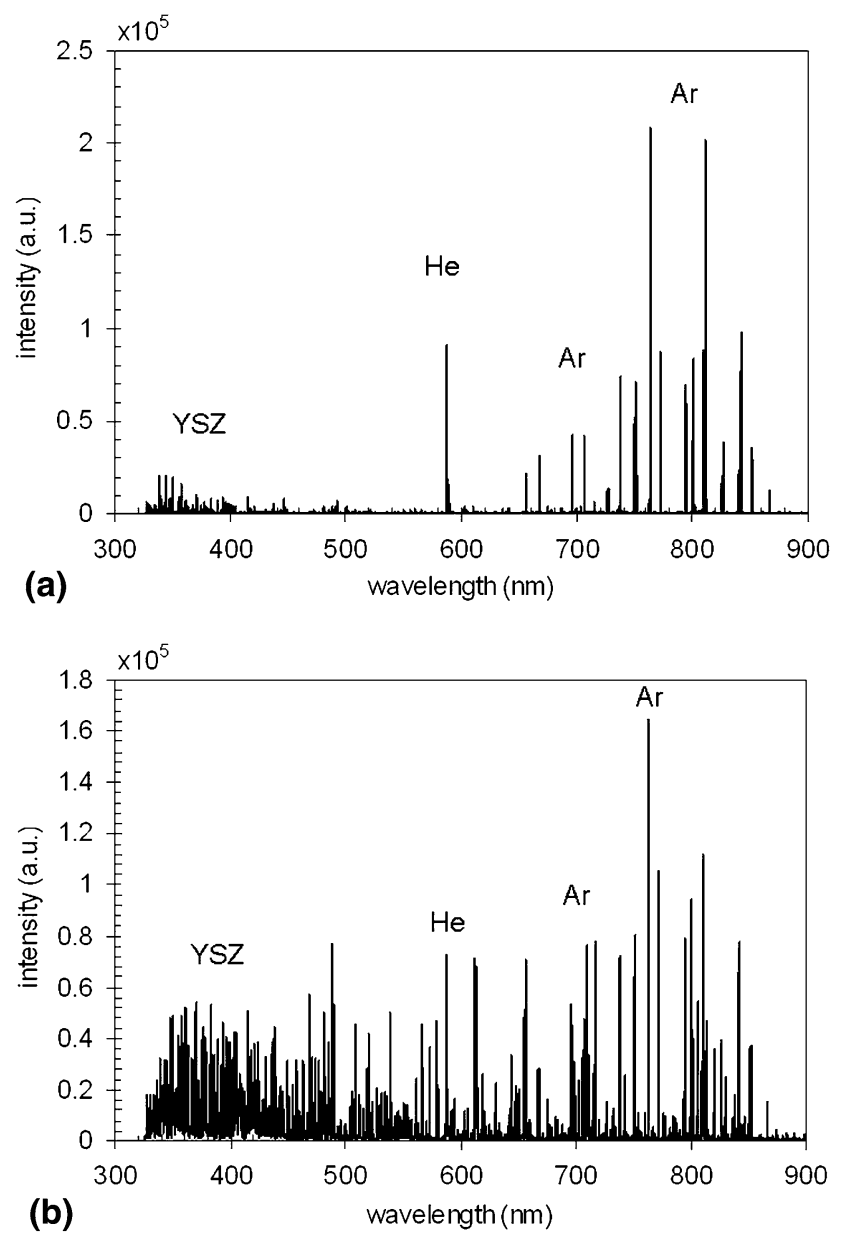

Fig. 3 Optical spectrum of the plasma jet $(\mathrm{Ar} / \mathrm{He})$ with $7 \mathrm{YSZ}$ corresponding to coatings having (a) no columnar structure and (b) with columnar structure 
higher substrate temperature is advantageous for the formation of a well-defined columnar microstructure. The YSZ columns grow perpendicular to the substrate surface. If the coating is applied to rough surfaces, then the growing columns interfere with each other and do not result in a homogeneous structure. If the coatings are applied on smooth surfaces, then the column axes orient themselves in parallel. Therefore, the surface roughness of the surface to be coated should not exceed a $R_{\mathrm{a}}$ value of $2 \mu \mathrm{m}$ to allow a homogeneous structure. The coating deposition out of the vapor onto the substrate takes place in the hot center of the plasma plume. Growth rates inside the plasma plume are very fast and can be more than $100 \mu \mathrm{m} / \mathrm{min}$. To avoid the overheating of the substrate from the high enthalpy of the plasma, the coating build up is obtained by producing a fast relative motion between the plasma jet and the substrate. The fast relative motion also ensures a homogeneous coating temperature distribution of the substrate. Deposition efficiencies of approx. $30-40 \%$ with a typical growth rate of approx. $0.1-0.2 \mu \mathrm{m} /$ pass can be achieved on flat metallic samples. This corresponds to a deposition rate on real parts such as turbine blades in the range of $\geq 10-20 \mu \mathrm{m} / \mathrm{min}$ depending on the geometry and size of the substrate. EB-PVD-produced coatings consist of a relatively homogeneous columnar structure composed of compact single columns. The bulky structure is only interrupted by a certain amount of intercolumnar gaps and voids between feather arms on the outer shell and a small amount of internal porosity (Ref 12, 13). Figure 4 shows a typical EB-PVD 7YSZ TBC microstructure in cross section.

In contrast, PS-PVD-produced columns consist of many fine needles with a high defect density and a high amount of internal porosity. A typical PS-PVD columnar structure with a layer thickness of approximately $250 \mu \mathrm{m}$ is shown in Fig. 5.

In order to characterize the columnar coatings and to validate the different morphologies, YSZ coatings with thicknesses in the range of $150-300 \mu \mathrm{m}$ were produced by PS-PVD on metallic test samples (Inconel 718, Rene N5,

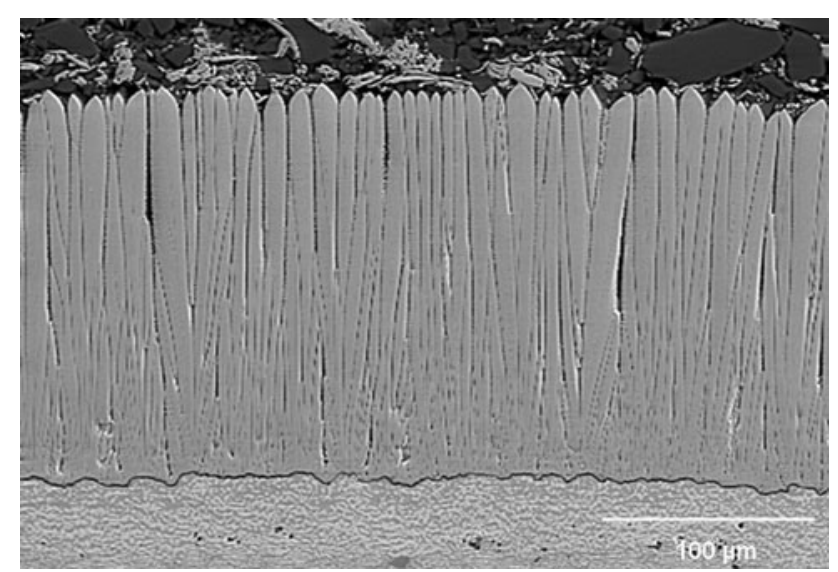

Fig. 4 Typical EB-PVD 7YSZ TBC microstructure in cross section (courtesy of U. Schulz, DLR, Inst. of Materials Research, Cologne, Germany) and Rene 142) having a vacuum plasma-sprayed MCrAlY or an electro chemical-deposited PtAl bond coat. Erosion tests, thermal cycling tests, and thermal conductivity measurements have been performed. Erosion resistance was measured using an erosion test rig according to the GE specification E50TF121. In these tests, an aluminum oxide powder with grain sizes in the range of $40-80 \mu \mathrm{m}$ is used as erodent and is accelerated at room temperature onto the TBC surface at an angle of $20^{\circ}\left( \pm 2^{\circ}\right)$ and with a pressure of 2 bar $( \pm 0.25$ bar $)$. The tube to accelerate the erodent is $95 \mathrm{~mm}$ long, and its standoff distance from the TBC surface was $102 \mathrm{~mm}$. The erosion resistance is measured as the time (in s) needed to erode $25 \mu \mathrm{m}$ of coating. Figure 6 shows the erosion resistance of different PS-PVD microstructures together with APS and EB-PVD coatings as reference. Previous measurements made on PS-PVD structures, labeled as PS-PVD1 in Fig. 6, showed low erosion resistance when compared with the EB-PVD. This can be explained by the fine internal needle structure of the single columns and the wide intercolumnar gaps between the columns giving a low mechanical strength for the coating.

With an adequate process and parameter optimization, the density of the coating structure was improved by reducing the inter-columnar gaps to a minimum. The erosion resistance of such an optimized parameter is

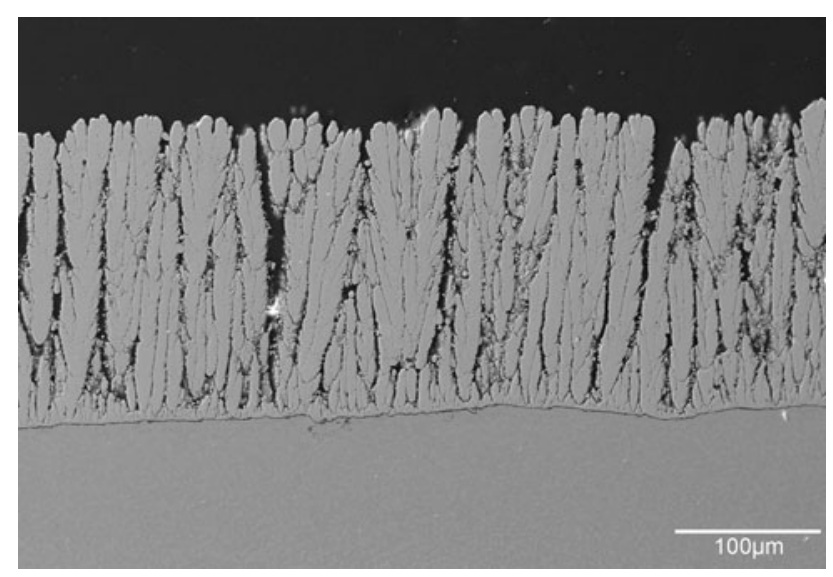

Fig. 5 Columnar TBC top layer deposited with PS-PVD1 on a MCrAlY bond coat

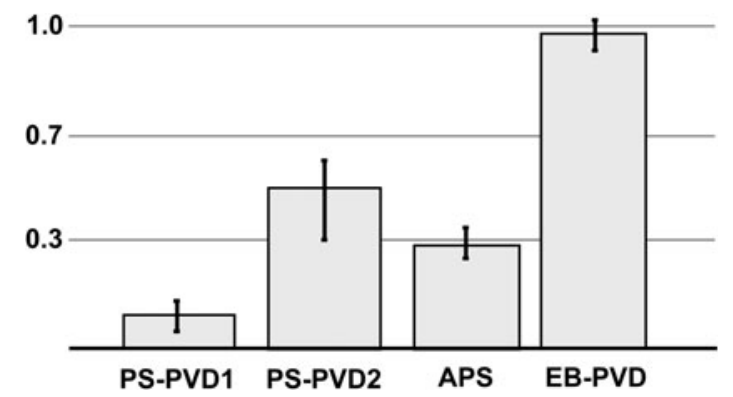

Fig. 6 Relative erosion resistances of different coatings produced by PS-PVD (PS-PVD1, not optimized, PS-PVD2, optimized), APS and EB-PVD as reference

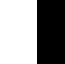




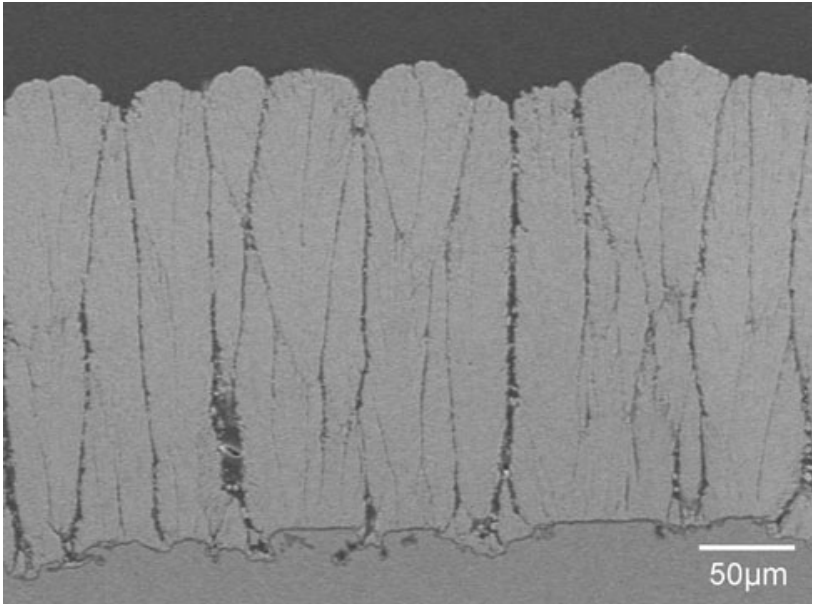

Fig. 7 Optimized PS-PVD columnar TBC structure deposited on a MCrAlY bond coat

shown on the measurement labeled "PS-PVD2" in Fig. 6. An erosion resistance value between the resistance of APS and EB-PVD coatings could be achieved. A cross-section of the optimized columnar structure (PS-PVD2) is shown in Fig. 7.

Furnace cycling tests (FCT) were performed to determine the performance of the TBC coating in terms of strain tolerance. A standard test cycle of the coated part is made in atmosphere between $1135^{\circ} \mathrm{C}$ and room temperature (Ref 14). The heat-up phase is 6 min with a hold period of $50 \mathrm{~min}$ followed by a cooling time of $4 \mathrm{~min}$. In order to validate coating spallation, the hourly cycle is interrupted for a period of $4 \mathrm{~h}$ every $24 \mathrm{~h}$. The $4 \mathrm{~h}$ interval also allows water coming from the humidity of the air to infiltrate the structure when it is at room temperature. The failure criterion is defined as the time or the number of cycles needed for the onset of coating spallation or buckling of at least $25 \%$ of the total coating surface. The highest FCT value was obtained with the PS-PVD columnar structure which achieved more than 700 cycles without any failure of the coating. These results have been obtained on substrates having a PtAl bond coat. Substrates with a MCrAlY bond coat and a PS-PVD TBC also performed better than EB-PVD, but showed much more variance and sensitivity to the process parameters, such as preheating temperature, surface roughness and TGO (thermally grown oxide) formation due to bond coat oxidation. FCT results of substrates with PS-PVD TBC coatings on different bond coats are shown in Fig. 8 and compared with the EB-PVD TBC/MCrAlY coating systems used as reference. It is assumed that a defined preoxidation of the bond coat producing a thin $\alpha-\mathrm{Al}_{2} \mathrm{O}_{3}$ layer before the TBC deposition can further increase the performance of the PS-PVD TBCs. Such an approach was successfully verified for other coating systems by other authors (Ref 15-17).

Thermal conductivity measurements of different PS-PVD coating structures were conducted using the laser flash method (Netzsch Thermal Analysis, Selb, Germany). The measurement of the thermal conductivity of PS-PVD

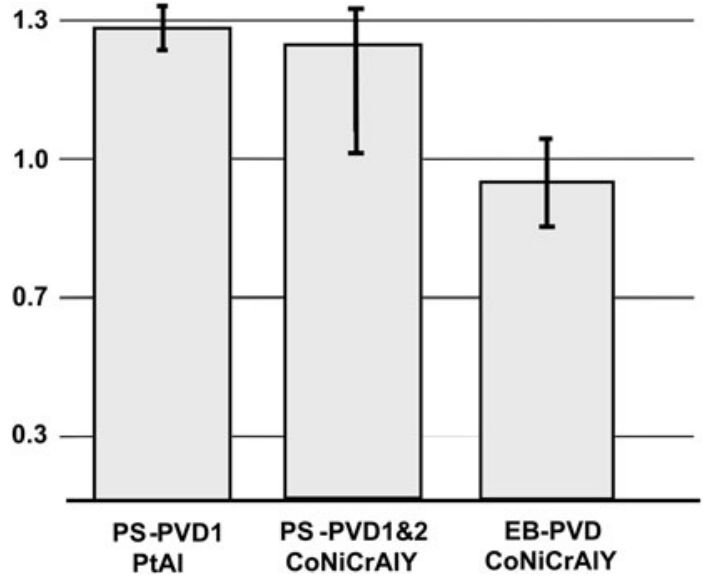

Fig. 8 Relative FCT results of samples with different bond coats and PS-PVD topcoats and the EB-PVD as reference

TBC coatings is approx. $0.8 \mathrm{~W} / \mathrm{mK}$ at room temperature without any noticeable change up to $1000{ }^{\circ} \mathrm{C}$. The superior results obtained can be explained by the higher porosity and defects of the PS-PVD coating microstructure as it was shown before.

Real gas turbine blades have been coated with TBC to demonstrate the ability of the PS-PVD technology to uniformly cover parts with complex geometries. In this case, the microstructure of the coating was columnar at all the locations on the substrate. The coating was homogenously distributed with a thickness range of approx 150$200 \mu \mathrm{m}$. The thickness is slightly lower on the suction side and higher at the leading edge. The columnar structure was also produced along the fillet region but with a slightly reduced coating thickness of approx. 100-120 $\mu \mathrm{m}$.

\section{Process Application on Turbine Parts}

The focus of the development of the PS-PVD technology is to coat complex-shaped turbine components by taking advantage of the high forced gas stream of the plasma jet which contains the coating material in vaporized form.

\subsection{Coating of Multiple Air Foils}

Conventional thermal spraying and EB-PVD processes can only produce coatings on surfaces which are in direct line-of-sight to the coating source, for example, the plasma gun or targets. If the stream of the coating material is interrupted by undercuts or in the particular case by a second airfoil, then the hidden surface will not be coated. This is the reason why it is difficult to coat double nozzle guide vanes with conventional techniques. In the case of a double vane, the two airfoils shadow each other and create large areas which cannot be covered with a line-of-sight coating process.

In the PS-PVD process, the coating material (YSZ) is injected inside the plasma gun where it vaporizes and is transported in an expanding supersonic plasma gas stream. 
Owing to the high velocity and the large dimension of the plasma jet, the gas stream is able to flow around complex geometries and is "forced" to go through the shadowed areas. Since the coating material is in vapor phase and transported inside this stream, the coating deposit is made whenever the plasma is in contact with the surface, thereby making the PS-PVD a non-line-of-sight coating process. Therefore, the entire surface of a doublenozzle-guided vane can be coated with a TBC, with a simultaneous coverage of both sides of the airfoils and the platforms during the same spray run.

A simplified double vane dummy with parallel platforms and solid airfoils was employed to demonstrate the non-line-of-sight possibilities of the PS-PVD process. The drawing of the vane dummy is shown in Fig. 9. It has a cubic dimension of $95 \times 135 \times 60 \mathrm{~mm}$. The substrate material is a solid chrome nickel-based stainless steel. No bond coat was applied or interface modifications were made before applying the TBC coating.

During the spray process, the part rotates on its axis, and, at the same time, the gun performs a tilt movement producing a sweep motion of the plasma jet over the substrate between the two platforms. The reversal spot is slightly outside of the vane to prevent overheating. The part is coated for $30 \mathrm{~min}$ at a temperature of approx. $1000{ }^{\circ} \mathrm{C}$. The coated part thus obtained is shown in Fig. 10.

The coating structure and its quality were analyzed in the laboratory. For this purpose, the double vane was cut and investigated using selective electron microscopy (SEM). Figure 11 shows the cut-up plan for the vane dummy, and each point corresponds to its respective location where a thickness measurement and a cross section were made.

Figure 12 shows the thickness distribution of the TBC on each airfoil and both platforms of one double vane. The numbers represent the location along the airfoil

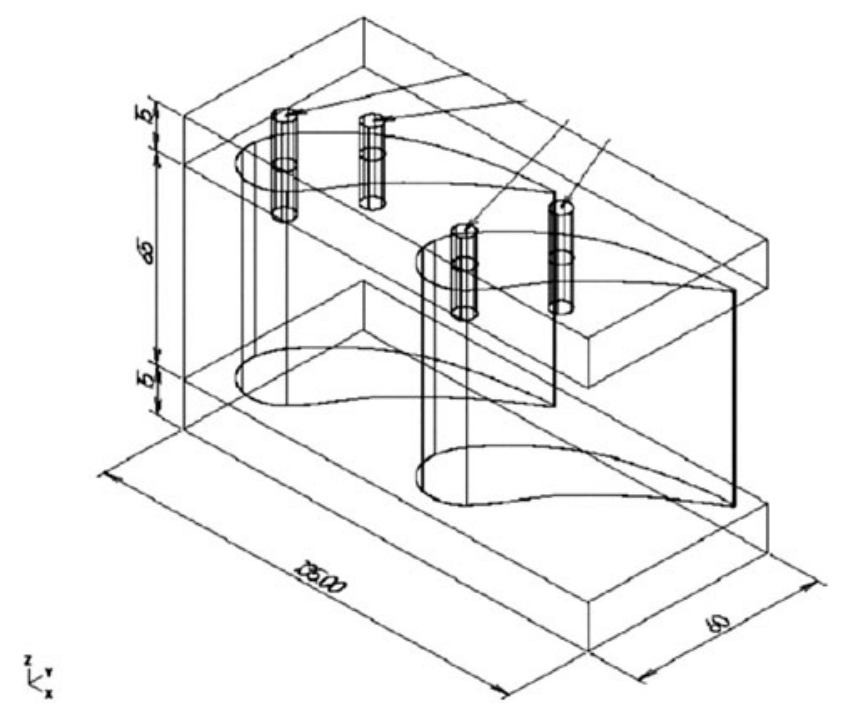

Fig. 9 Drawing of a simplified double vane dummy with parallel platforms and solid airfoils profile, and the letters the thickness measurement made on the platform. The percentage indicates where the cut has been made on the vane going from one platform $(0 \%)$ to the other one $(100 \%)$. In a real vane, the two platforms would have different shapes (inbound and outbound platform). The first two graphics show that both leading and trailing vanes have a continuous and homogeneous coating thickness distribution with an average coating thickness of $260 \mu \mathrm{m}$ and a standard deviation of $60 \mu \mathrm{m}$. These profiles look very similar to the thickness distribution of a single blade. The locations where the thickness is slightly higher are the lead of the vane (Ref 6) and the top part of the trail of the airfoil (Ref 1). These areas are sensitive to the dynamics of the flow, such as turbulences and the temperature of the substrate. The second graph of Fig. 12 also show that the trailing airfoil presents a slightly higher thickness variation in the coating than the leading airfoil, again showing the effect of the dynamics of the flow. The lower coating thickness on the airfoil

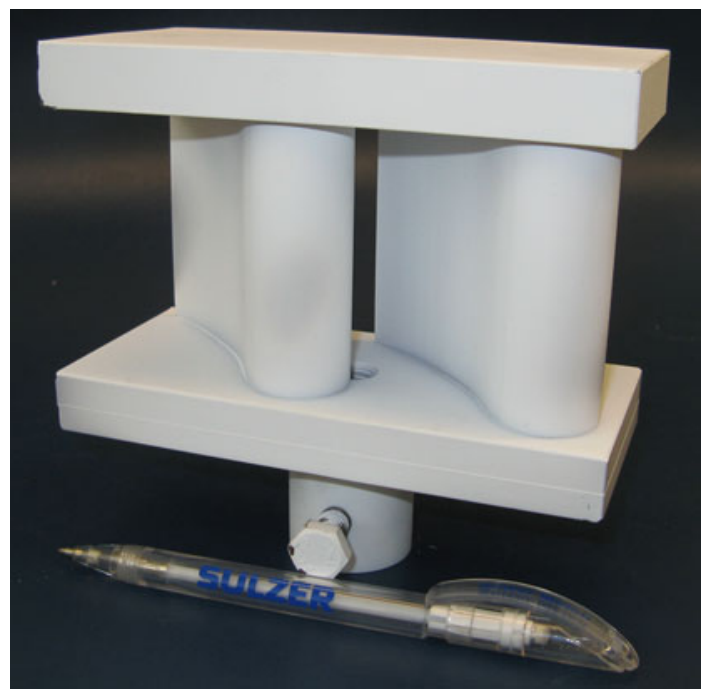

Fig. 10 Double vane dummy with a YSZ TBC coating, deposited with PS-PVD

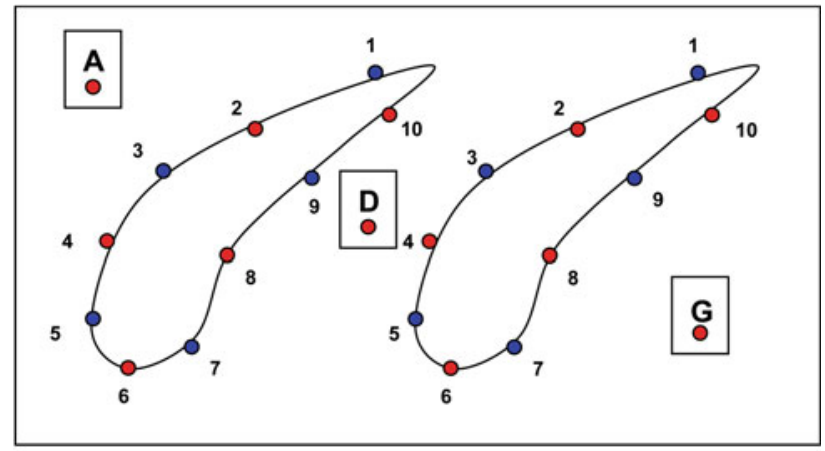

Leading Vane

Trailing Vane

Fig. 11 Cut-up plan for the vane dummy and the location for the thickness measurements and cross section 

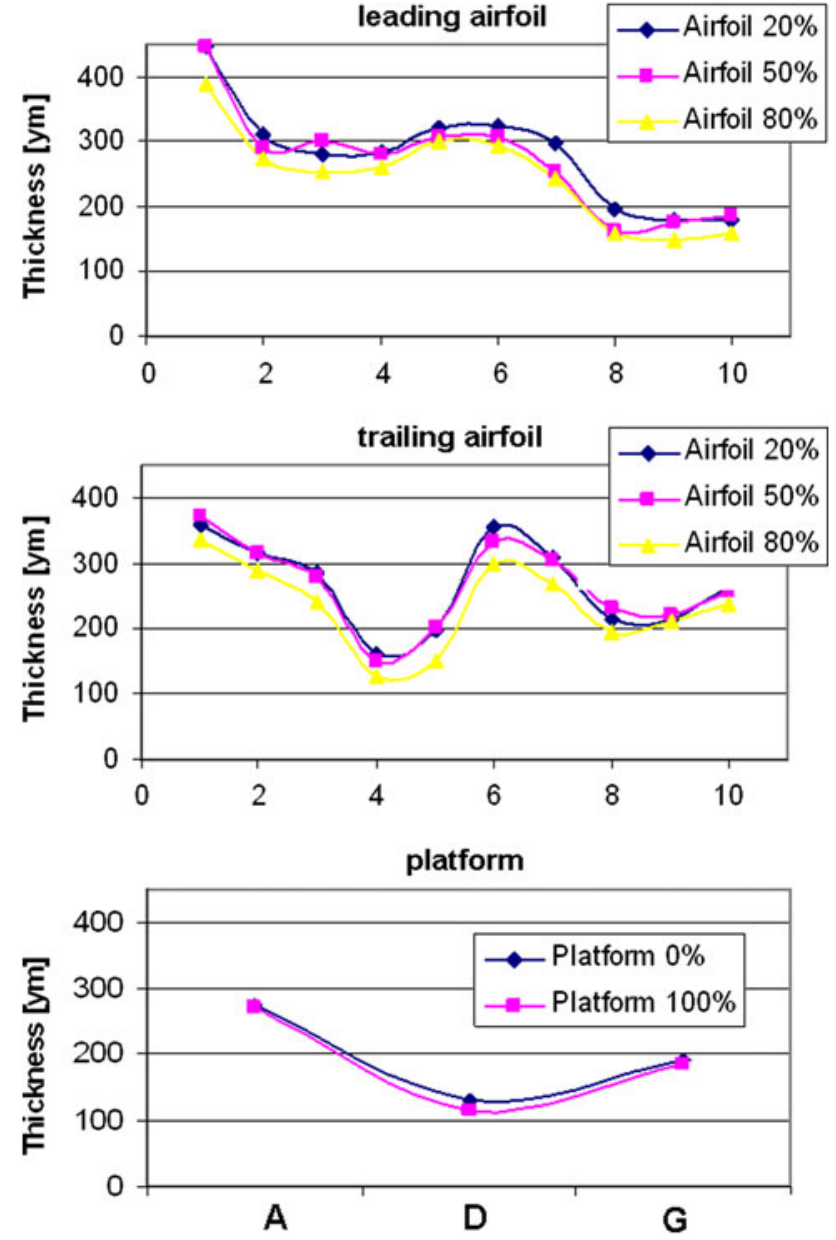

Fig. 12 Coating thickness distribution of a PS-PVD coated dummy double vane after 30 min of coating operation

corresponds to a stagnation point of the plasma jet flow on the surfaces, both on the top of the airfoil (Ref 4) and the bottom (Ref 8).

Since the dummy double vane is symmetric, there is no variation in the thickness between the different cuts $(20,50$, and $80 \%)$. This shows that the plasma jet covers the blades uniformly and does not produce any shadows originating from the platforms. The platforms which are more difficult to cover, as they are parallel to the plasma jet still, have a coating thickness of $200 \mu \mathrm{m}$ with a minimum of $120 \mu \mathrm{m}$ between the airfoils (area D). The platforms are especially taken care of by optimizing the gun movement and the angle to allow achieving a good deposition on the hidden areas.

The microstructure of the coating was also evaluated by performing SEM analysis along the airfoils and on the platforms - at the same locations used for the thickness measurements. In general, the TBC coating has a good columnar microstructure at any location on the vane. A high-quality columnar-structured coating can even be seen in the shadowed areas such as the points 8 (leading airfoil), D (platform), and 4 (trailing airfoil) as shown in Fig. 13.
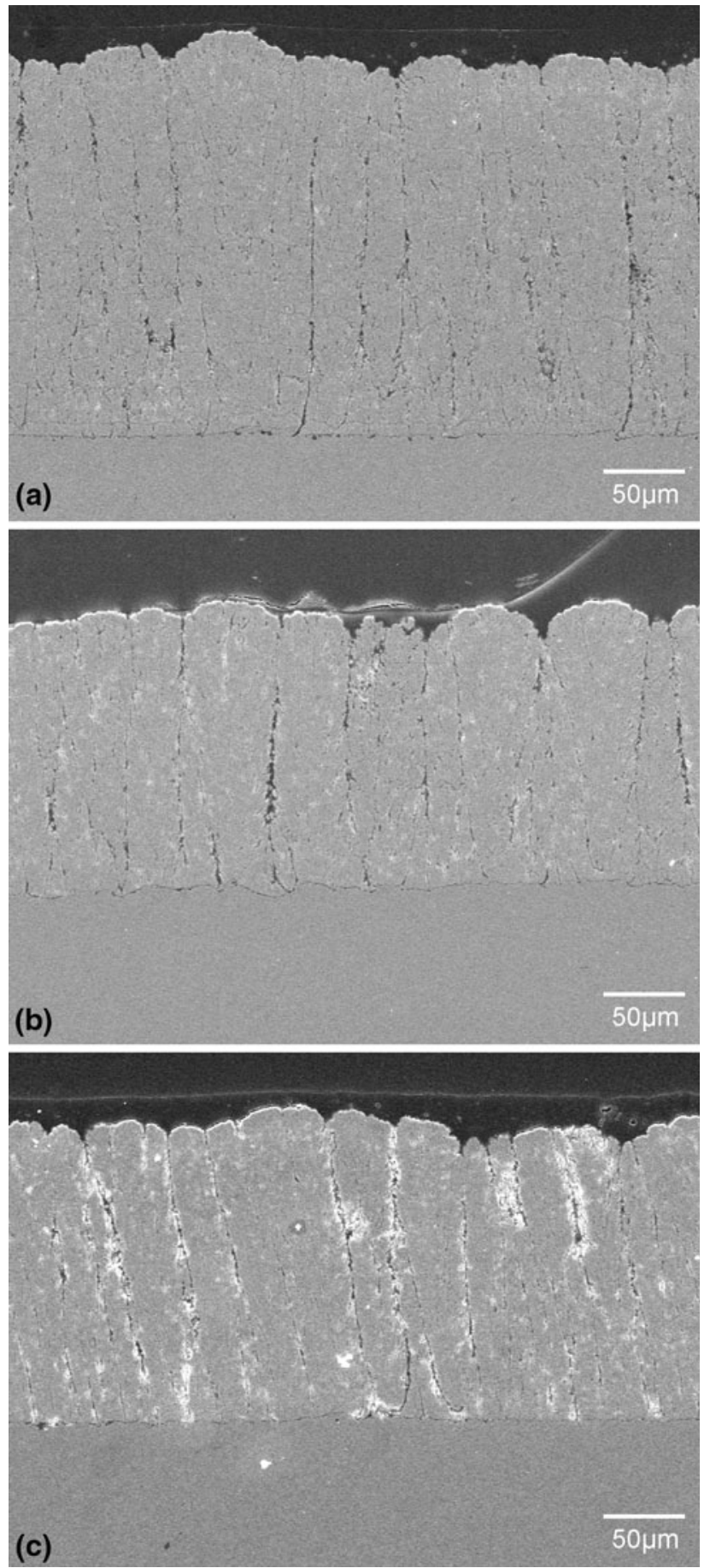

Fig. 13 Columnar microstructure at shadowed areas of the double vane dummy. (a) Measuring point 8 leading airfoil, (b) measuring point $\mathrm{D}$ platform, and (c) measuring point 4 trailing airfoil

These spray trials show that with the PS-PVD process, it is possible to coat TBCs on double vanes with complex geometry. Even shadowed areas get coated homogeneously with the desired columnar microstructure. It is demonstrated that, within a single coating run of $30 \mathrm{~min}$, a medium-sized double vane can be completely coated with 
a TBC layer up to a thickness of $260 \mu \mathrm{m}$ on the airfoils and $200 \mu \mathrm{m}$ on the platforms.

The feasibility studies have been made on a single part, which demonstrate remarkable results in coating quality and performance. However, the PS-PVD has not yet shown all its capabilities. The large plasma jet can also be employed to coat several parts simultaneously in one single run. The idea is to exploit this non-line-of-sight feature of this process for not only one double vane, but also for multiple part handling, so that several double vanes could be coated in a single run. This shows that the PS-PVD is not only a unique coating process for producing coatings in hidden areas but also, a competitive process due favoring the high throughput, high deposition rates, and high quality of the deposited TBC.

\section{Summary}

The PS-PVD technology uses a reduced ambient pressure down to $0.1 \mathrm{kPa}$ (1 mbar) and an increased power level of a modified plasma gun to achieve special plasma characteristics. With this technology, the injected powder material is not only molten into liquid droplets but evaporated to build up a coating. In the case of YSZ, it was possible to produce coatings from the vapor phase using a thermal spray process where the coating has a unique columnar microstructure, which so far has been obtained only by other vapor-phase deposition processes such as EB-PVD. The single columns consist of many fine needles with a high defect density and a high amount of internal porosity. With this morphology, the coatings have special characteristics which are advantageous for gas turbine applications. The coatings produced by PS-PVD process have proven to be highly strain tolerant during furnace cycling tests, and offer a low thermal conductivity. The erosion resistance is lower than that of EB-PVD coatings but at a level of standard APS TBC coatings with $15 \%$ porosity. Real gas turbine substrates as well as simplified double vane dummies were coated to demonstrate the ability of PS-PVD to coat shadowed areas and areas which do not fall within the line-of-sight of the coating source. This technology offers a high potential to support the development of new non-line-of-sight coating solutions for improved TBC systems and their application under production relevant conditions with increased economic benefit.

\section{References}

1. P. Ambühl and P. Meyer, Thermal Coating Technology in Controlled Atmospheres (ChamPro $\left.{ }^{\mathrm{TM}}\right)$, Proceedings of the ITSC, E.
Lugscheider and P.A. Kammer, Ed. (Düsseldorf, Germany), DVS-Verlag, 1999, p 291-292

2. S.G. Terry, J.R. Litty, and C.G. Levi, Evolution of Porosity and Texture in Thermal Barrier Coatings Grown by EB-PVD, Elevated Temperature Coatings, Science and Technology III, Proceedings of TMS Annual Meeting, J. Hampikian and N.B. Dahotre, Ed. (San Diego, USA), The Minerals, Metals and Materials Society, Warrendale, USA, p 13-25

3. B.R. William and E.J. Douglas, Electron Beam Physical Vapor Deposition Apparatus, U.S. Patent 6,983,718, 2006

4. M. Kenneth, Thermal Barrier Coating, US Patent 6,689,487, 2004

5. M. Gindrat, J.L. Dorier, Ch. Hollenstein, M. Loch, A. Refke, A. Salito, and G. Barbezat, Effect of Specific Operating Conditions on the Properties of LPPS Plasma Jets Expanding at Low Pressure, Proceedings of the 3rd ITSC, E. Lugscheider and C.C. Berndt, Ed. (Essen, Germany), DVS-Verlag, 2002, p 459-464

6. E. Muehlberger, Method of Forming Uniform Thin Coatings on Large Substrates, U.S. Patent 5,853,815, 1998

7. J.L. Dorier, M. Gindrat, Ch. Hollenstein, M. Loch, A. Refke, A. Salito, and G. Barbezat, Plasma Jet Properties in a New Process at Low Pressure for Large Area Thin Film Deposition, Proceedings of the 2nd ITSC, C.C. Berndt, et al., Ed. (Singapore), ASM International, 2001, p 759-764

8. A. Refke, D. Hawley, J. Doesburg, and R. Schmid, LPPS Thin Film Technology for the Application of TBC Systems, Proceedings of the International Thermal Spray Conference, E. Lugscheider and D. von Hofe, Ed., May 2-4, 2005 (Basel, Switzerland), DVS-Verlag, 2005, p 438-443

9. A. Refke, G. Barbezat, J.L. Dorier, M. Gindrat, and Ch. Hollenstein, Characterization of LPPS Processes Under Various Spray Conditions for Potential Applications, Proceedings of the 4th ITSC, R. Basil, B.R. Marple, and Ch. Moreau, Ed. (Orlando, Florida), ASM International, 2003, p 581-588

10. M. Gindrat, A. Refke, and R. Schmid, Process Characterization of LPPS Thin Film Processes with Optical Diagnostics, Proceedings of the 7th ITSC, on CD-ROM, B.R. Marple, M.M. Hyland, Y.-C. Lau, C.-J. Li, R.S. Lima, and G. Montavon, Ed., May 14-16, 2007 (Beijing, China), ASM International, 2007, p 705-710

11. B. Jodoin, M. Gindrat, J.L. Dorier, Ch. Hollenstein, M. Loch, and G. Barbezat, Modelling and Diagnostic of a Supersonic DC Plasma Jet Expanding at Low Pressure, Proceedings of the 3rd ITSC, E. Lugscheider and C.C. Berndt, Ed. (Essen, Germany), DVS-Verlag, 2002, p 716-720

12. A. Flores Renteria, B. Saruhan, U. Schultz, H.-J. RaetzerScheibe, J. Haug, and A. Wiedemann, Effect of Morphology on Thermal Conductivity of EB-PVD PYSZ TBCs, Surf. Coat. Technol., 2006, 201(6), p 2611-2620, ISSN 0257-8972

13. U. Schulz, S.G. Terry, and C.G. Levi, Microstructure and Texture of EB-PVD TBCs Grown Under Different Rotation Modes, Mater. Sci. Eng. A, 2003, 360, p 319-329

14. R. Hillery, et al., Coatings for High-Temperature Structural Materials: Trends and Opportunities, National Academy Press, 1996, p 26-33, ISBN 0-309-05381-1

15. H. Lau, C. Leyens, U. Schulz, and C. Friedrich, Influence of Bond Coat Pre-Treatment and Surface Topology on the Lifetime of EB-PVD TBCs, Surf. Coat. Technol., 2003, 165, p 217-223

16. V.K. Tolpygo and D.R. Clarke, The Effect of Oxidation PreTreatment on the Cyclic Life of EB-PVD Thermal Barrier Coatings with Platinum-Aluminide Bond Coats, Surf. Coat. Technol., 2005, 17, p 1276-1281

17. I. Spitsberg and K. More, Effect of Thermally Grown Oxide (TGO) Microstructure on the Durability of TBCs with PtNiAl Diffusion Bond Coats, Mater. Sci. Eng. A, 2006, 417, p 322-333 